\title{
A Life-Saving Therapy: The Theory-Building Case of "Cora"
}

\author{
MARGRETHE SEEGER HALVORSEN, ${ }^{\mathrm{a}, \mathrm{b}}$ KIRSTEN BENUM, ${ }^{\mathrm{a}}$ \\ HANNE HAAVIND, ${ }^{\mathrm{a}} \&$ JOHN MCLEOD ${ }^{\mathrm{a}}$ \\ ${ }^{a}$ Department of Psychology, University of Oslo, Norway \\ ${ }^{b}$ Correspondence regarding this article should be sent to Margrethe Seeger Halvorsen, Department of Psychology, \\ University of Oslo, Pb. 1094 Blindern, 0317 Oslo, Norway \\ Email: m.s.halvorsen@psykologi.uio.no
}

\begin{abstract}
The present paper presents a case study of long-term (121 sessions over three years), integrative therapy with "Cora," a client with a history of severe relational trauma that had led to difficulty in forming close relationships, and a history of hospitalization resulting from a series of suicide attempts. Despite these challenges, Cora reported a highly satisfactory outcome at the end of therapy. Using the format of a theory-building case study (McLeod, 2010; Stiles, 2007), qualitative analysis of session evaluations, session transcripts, and post therapy interviews were used to investigate how both the client and therapist understood the process of therapy and why it had been successful. Data from quantitative process and outcome measures were analyzed to provide contextual information. In spite of repeated challenges and difficult therapeutic situations, Cora and the therapist were able to establish a recurring pattern of interaction that they found relevant and productive and that was characterized by persistence. Other helpful aspects of the therapy process included acting with courage, and the use of symbolic representations of their accomplishments. The results contribute to our understanding of the process of therapy with clients who have been exposed to severe relational trauma. The discussion includes reflection on methodological issues associated with mixed-methods case study research in psychotherapy.
\end{abstract}

Key words: courage; helpful therapeutic processes; integrative psychotherapy; Interpretative Phenomenological Analysis; relational trauma; expert therapists; therapist variable; case study; clinical case study

\section{CASE CONTEXT}

From the point of view of developing practical knowledge around how psychotherapy can be helpful, it is valuable to analyze cases where difficulties were clearly felt on both sides. Cases with a rather slow and troubled development of a viable working alliance may reveal how mutual trust, an emotional bond or sense of connection, and a sense of progress, are accomplished through joint action by both client and therapist. There are two main ways in which research into difficult cases can contribute to practice. First, within the psychotherapy literature there is a general acknowledgement that certain groups of clients are experienced by clinicians as difficult to treat (Munich \& Allen, 2013). Such clients may be refused treatment, 
drop out of therapy, or record poor outcomes despite lengthy treatment. The study of difficult cases makes it possible to identify strategies through which such clients may be more effectively helped. Second, the accomplishment of arriving at a satisfactory outcome following difficult therapy may represent important evidence regarding the nature of therapist expertise. There is evidence that therapists are more likely to record similar outcomes in well-motivated clients with moderate levels of problem severity, and that differences between more-effective and lesseffective therapists are more apparent in the context of therapy with difficult-to-treat clients with chronic difficulties (Saxon \& Barkham, 2012). In relation to the development of practically relevant research into therapist expertise, it is therefore particularly valuable to examine the skills and strategies used by therapists in challenging cases.

Research into the attitudes and qualities of effective therapists has found that facilitative interpersonal skills (Anderson, Ogles, Patterson, Lambert, \& Vermeersch, 2009), professional self-doubt (Nissen-Lie, Monsen, \& Ronnestad, 2010), and professional self-doubt allied to a positive self-image (Nissen-Lie et al., 2015) represent general therapist qualities that are associated with good outcomes. In relation to effectiveness in long-term therapy, therapists' qualities such as caution, kindness and supportiveness have been found to differentiate between more-effective therapists and those who report poorer client outcomes (Heinonen, Lindfors, Härkänen, Virtala, Jääskeläinen, \& Knekt, 2014; Heinonen, Lindfors, Laaksonen, \& Knekt, 2012; Sandell, Blomberg, Lazar, Carlsson, Broberg, \& Schubert, 2000; Sandell, Lazar, Grant, Carlsson, Schubert, \& Broberg, 2007). However, no research-based evidence is currently available regarding therapist qualities that may be specifically required for effective work with difficult cases. In addition, with the exception of interpersonal skills, the therapist attributes identified in existing studies primarily describe trait-like attitudes and qualities rather than competencies that can be enhanced through deliberate action and practice (Chow, Seidel, Miller, Kane, Thornton, \& Andrews, 2015; Miller, Hubble, Chow, \& Seidel, 2013), a generally accepted attribute of professional expertise (Tracey, Wampold, Lichtenberg, \& Goodyear, 2014).

\section{THE CLIENT}

Cora presented a distinctive array of difficulties. She had a childhood history of severe emotional, physical, and sexual abuse by her mother and her mother's friends, which had resulted in, among others, extreme difficulty in trusting other people and forming relationships, problems in maintaining work roles, previous unsuccessful therapy, and repeated life-threatening suicide attempts that had resulted in several hospitalizations.

Prior to the present episode of treatment, Cora was hospitalized due to a serious suicidal attempt. When she started the present episode, its length was not predetermined; it evolved into a three-year therapy. The present case study covers this three-year therapy period. (It should be noted that at the end of the three years, Cora was still in need of treatment for her remaining distress. In line with this, she started a 12-week, group-focused, specialized treatment program in an inpatient unit for trauma treatment informed by recent trauma research and theory. After completing the 12 weeks, Cora resumed individual therapy with her original therapist. However, no data were collected on Cora's therapy after the three-year episode covered in the present case study.) 
Cora presented herself at the outset as a person suffering from severe depression. She was single with no children, had experienced only abusive relationships with men during her adult life and had no intimate friendships. She was academically educated, and had been on disability pension for two months before the referral. For many years her work had involved professional relationships with other people. She was seeking individual psychotherapy through a public out-patient clinic. Cora described her previous episodes of therapy as not having been particularly helpful.

In addition, at the commencement of the episode of therapy described in the present report, she insisted on her right to commit suicide. From the start, her therapist certainly regarded her as a case that would present him with substantial challenges.

In compiling this case analysis, we arrived at a position of believing that standard diagnostic categories would neither respect, nor do justice to, the life of this client. Instead, we have attempted to describe her life in as much detail as possible, to enable readers to make up their own minds about how to answer a question that is always problematic in case study research: what is this a case of?

In choosing a title for the case, we have opted to follow the shared view of both client and therapist regarding what was, for them, the fundamental meaning of their work together: saving a life.

\section{GUIDING CONCEPTION}

In the context of the case analysis that follows, in order to make it possible to develop connections between the process of therapy in this case, and other comparable studies, we have decided to focus in particular on the existence of early relational trauma as a defining characteristic of Cora's life, and core theme within her therapy. We define early relational trauma as a negative experience with a caregiver within the first few years of life, that is marked by active and intrusive attack rather than (or as well as) mere neglect. On the basis of extensive clinical literature, we conclude that this type of early experience has been found to result in lifelong difficulties in intimacy and forming attachments, lack of trust, and fearfulness or terror around the possibility of closeness with another person. In terms of the distinction introduced by Killingmo (1989), Cora could be regarded as a person struggling to address underlying life deficits, rather than as someone who had benefitted from a secure start in life and then at a later stage of development encountered destabilizing conflicts.

The process of therapeutic help for individuals with this type of pattern of early relational trauma has been extensively studied within the psychotherapy research literature. Individuals who have been actively harmed on a cumulative basis in childhood by caregivers or other attachment figures may require therapy in which it becomes possible to revise inner working models of attachment relationship (Pearlman \& Courtois, 2005). The characteristics of the therapeutic relationship associated with effective treatment in such situations include the provision of respect, information, connection and hope (Pearlman \& Courtois, 2005) and also the active involvement of the therapist in transference work that allows relational learning to occur in the context of moment-by-moment therapist-client interaction (Høglend et al., 2011; 
Ulberg, Marble, \& Høglend, 2009). The concept of “earned-security” is also relevant to an understanding of such clients. Pearson, Cohn, Cowan, and Cowan (1994) found that a significant proportion of individuals with negative attachment experiences in childhood were nevertheless able to exhibit secure attachment patterns in adult life, on the basis of involvement of alternative support figures (Saunders, et al., 2011). Clearly, a relationship with a psychotherapist represents a potentially curative form of support.

With some clients suffering from early relational trauma, the co-occurrence of suicidality may result in the introduction of a therapeutic protocol that is explicitly aimed at the minimization of life-threatening behaviors (Ellis et al., 2012). The extent to which such therapeutic responses are handled represents a crucial issue in such treatment. There is a possibility that suicide-prevention interventions may undermine the operation of therapeutic pathways intended to promote attachment security.

By exploring the ways in which complex processes unfold over time, within a specific context, case study methodology represents a valuable approach to investigating what happens in difficult cases of therapy. Detailed accounts of therapy with difficult cases associated with psychotic features (Atwood, 2012; Karon, 2008; Terry, 2003, 2004, 2005, 2010) have emphasized the importance of therapist belief in a set of treatment principles, allied to willingness to be firm and patient in the repetitive application of these principles over a prolonged period of time.

In this context, it has been possible to locate three published case studies that focus on therapy with female clients who were similar in key respects to the client in the current case, in suffering from severe early relational trauma, long-term emotional and relationship difficulties, and suicidal intentions. These studies present richly described, contextualized explorations of therapy, and each identifies the core change processes within the case. These change processes turn out to be distinctively different, including the development of a capacity for mentalization (Stein, \& Allen, 2007); firm communication by the therapist of a genuine sense of caring (Schechter, Goldblatt, \& Maltsberger, 2013); and use of CBT exposure interventions for panic disorder within a secure therapeutic relationship (Oestrich, 1992). The common thread across these three case studies was the necessity for a committed, caring and persistent therapeutic relationship. Other than that, these cases suggest that quite different technical interventions may be equivalent in efficacy with such clients, as long as the therapeutic alliance is sufficiently strong.

The current study presents a theory-building case study (McLeod, 2010; Stiles, 2007) that makes use of the capacity of single-case analysis to develop a model of complex processes in a particular type of case. Our aim in this case study has been to explore the ways in which the client and her therapist made sense of the process of their work together in terms of their understandings of what was helpful and how it was helpful. Our assumption was that accessing and analyzing this type of "insider" knowledge would make it possible for us to highlight aspects of therapist competence, expertise and action patterns that hold relevance for success in "difficult" cases in general, or for this particular form of difficult case. 


\section{METHOD}

A narrative qualitative approach, using Interpretative Phenomenological Analysis (Smith, Flowers and Larkin, 2009) was used as an overarching framework to guide our analysis as to how the client and therapist made sense of the lived experience of therapy. In addition, data from quantitative process and outcome measures were used to establish points of contact between the present case and general process and outcome benchmark indicators.

\section{Case Selection}

The selected case was one of 50 therapist-client dyads comprising a larger processoutcome study of the interpersonal aspects of psychotherapy in a sample of highly experienced therapists and their clients (Rønnestad, 2009). As reflected in the methodology of Cora's case study, the larger study brought together a number of elements that have been associated with successful therapy and best practice psychotherapy research: namely, "1. [a] focus on interpersonal process; 2. the collection of continuous data (i.e., from each therapy session); 3. [the] collection of continuous data from multiple perspectives, i.e. both from patient and therapist after each session, and digital recordings making external observation possible; 4 . the combination of qualitative and quantitative data; [and] 5. the study of expert therapists" (p. 4).

Overall, the results from this larger project indicate positive outcome on a group level from pre- to post-treatment, with a large effect size $(d=.86$; Rønnestad, Gullestad, Halvorsen, Haavind, Lippe, Nissen-Lie, \& Reichelt, 2014, June). In accordance with our intention to explore alliance work in the area of bond formation, we selected a theoretically-relevant case, characterized by a long and difficult history of alliance formation with a good ending as reported by both client and therapist. The client, Cora (a woman in her late forties), and the therapist (a man in his mid-sixties) met for 121 sessions during a period of three years. The alliance was negotiated all the way through. From the very outset the client presented a claim that she would reserve an unconditional right to commit suicide. Further, she would not give up her habit of deliberate self-harm. Instead she expected the therapist to accept this as following from her psychological needs. Having been in psychotherapy before, she was fully aware that her demand for an unconditional right to commit suicide violated the basic notions about how to create a goal for the outcome of their work together.

\section{Participants}

\section{Client}

Cora is described in Section 2 above.

\section{$\underline{\text { Therapist }}$}

The therapist had 31 years of clinical experience; he had an excellent reputation among his peers; and he was an experienced supervisor. For many years he had worked in an outpatient clinic, and was able to offer long-term therapy to some of his clients. From the referral he considered this client as being in need of therapy, but also as a client who would present special 
challenges. Therefore, he could not decide upon the length of the therapy at onset.

He described his therapeutic orientation as integrative; drawing on narrative, systemic, humanistic and psychodynamic perspectives. He had previous experience with clients with a variety of conditions, but no specific training in trauma treatment. The therapist and the client usually met weekly, with some extra sessions in between due to intensification of her problems, for a total of 121 sessions over a period of three years. At one point during the treatment period, the therapist assisted Cora to negotiate some time in a supportive residential center, due to increased suicidal risk.

\section{$\underline{\text { Researchers }}$}

All four authors are researchers who also work as psychotherapists. They share an engagement in facilitating integration between psychotherapy research and clinical practice, and they consider systematic and comprehensive analyses of cases to be suitable in this respect.

The first author (MSH) is associate professor and has fourteen years of psychotherapeutic experience. Her theoretical orientation may be described as integrative, theoretically informed by psychodynamic, developmental, humanistic and cognitive approaches.

The second author (KB) is also associate professor and has thirty years of clinical experience. Her theoretical orientation may be described as integrative; theoretically informed by humanistic, CBT and dynamic approaches, and she is a practitioner and a trainer in therapy for complex PTSD, dissociation and attachment trauma.

The third author (HH) is professor and has more than thirty years' experience from psychotherapy with children, families and adults, and her work is theoretically informed by developmental and interpersonal psychology. She is a practitioner and a trainer in qualitative research methods.

The fourth author (JM) is also a professor with twenty-five years of clinical experience. His approach is pluralistic, informed by person-centered, cognitive-behavioral and narrative theoretical perspectives. The first author conducted the post-therapy interview with the client. A member of the larger research project team, who is also a researcher and clinical psychologist, conducted the interview with the therapist. All four authors participated in data analysis.

\section{Ethical Procedures}

The therapist and subsequently his client were included in a larger study (Rønnestad, 2009), through routines that were approved by a Norwegian Regional Committee for Medical and Health Research Ethics (National Region South-East). The guiding idea was to set up a naturalistic study, which meant that the collection of data should not be too intrusive or timeconsuming for either therapist or client. Before the first session the therapist met with the 
client to invite her as a participant in the study and to give her the information that was relevant for her to give informed consent.

Data were stored according to a license awarded by the Norwegian Social Science Data Services. After the post-therapy interviews both the client and the therapist received a request from the first author to appear as the selected case for this article, and they both consented to this idea. Each of them was asked to read an earlier version of this article, and their additional comments and clarifications were added to the analysis and included here. Details about the therapist and the client have been transformed to provide anonymity.

\section{Data Collection}

The primary source of information in this study consisted of three forms of qualitative data, as described below.

\section{$\underline{\text { Post-Therapy Interviews }}$}

Within a month after ending treatment, client and the therapist were requested - in independent semi-structured interviews by two different interviewers - to recount their experiences from therapy and reflect upon the outcome and how the process had evolved from beginning to end. The authors used the interviews as markers into the other material, helping us to select relevant topics and sessions.

\section{$\underline{\text { Session Evaluations }}$}

A modified version of the Helpful Aspects of Therapy form (HAT; Llewelyn, Elliott, Shapiro, Firth, \& Hardy, 1988) was used. Compared to the original scheme, this version was reduced to three questions. Immediately after each session both client and therapist was asked to make a short written note about (1) what seemed to be significant themes for the actual session, (2) whether something seemed to have changed for the client (client version) or in the relationship between them (therapist version), and (3) whether this session had been beneficial to the client, marked on a scale from 0 (low) to 5 (high). The notes from the client were collected in sealed envelopes and therefore not accessible to the therapist. The authors used the session evaluations to get an indication of overreaching patterns across sessions, as well as a source of information regarding sessions in which specific themes were expressed.

\section{$\underline{\text { Audio-Recordings and Session Transcripts }}$}

Every session was audio-recorded. Based on readings of the post-therapy interviews and session evaluations of both participants, sessions of particular interest were selected and transcribed verbatim. For more information see below. Totally, the material comprised 494 pages (single-line spacing) of written material.

\section{$\underline{\text { Standardized Measures }}$}

In order to contextualize the case in relation to the wider population of clients, the following standardized measures were deployed. 
Working Alliance Inventory-Short Revised (WAI-SR; Hatcher \& Gillapsy, 2006) On this measure the therapist and the client rated the quality of their relationship on Working Alliance Inventory (WAI-SR; Hatcher \& Gillapsy, 2006) after session 3, 6, 12 and 20, and then at every $20^{\text {th }}$ session, until just after the last session.

The client completed two outcome questionnaires, as follows.

Outcome Questionnaire (OQ-45.2; Lambert, Burlingame, Umphress, Hansen, Vermeersch, Clouse, \& Yanchar, 1996). This is a measure of overall distress and was completed by the client after session 1, after session 3, 6, 12 and 20, and from there on every $20^{\text {th }}$ session, and finally after the last session.

Inventory of Interpersonal Problems (IIP-C-64; Alden, Wiggins, \& Pincus, 1990). This is a measure of interpersonal difficulties and was completed by the client at the same time as the OQ-45.

\section{Data Analysis}

It is important to acknowledge the methodological challenges associated with the analysis of case data in psychotherapy research. The process of therapy in this case generated a large amount of data reflecting client and therapist perspectives, and also the possibilities and constraints associated with different data collection strategies: interviews, session recordings, and measures. In order to guide our work with this material, we used the methodology of Interpretative Phenomenological Analysis (IPA: Smith, Flowers, \& Larkin, 2009; Smith, 2011) as an overarching framework. IPA is a method of systematic qualitative analysis based on phenomenological and hermeneutic principles, with an explicit idiographic focus. The primary purpose of IPA is to describe and analyze episodes of lived experience considered by informants to be of personal significance to their lives. While more typically based on interview data with sample sizes of 3-12 informants, IPA has also been applied in a number of case study investigations (Bramley \& Eatough, 2005; Eatough \& Smith, 2006a,b; Quinn, Schofield, \& Middleton, 2012). In IPA, even when multiple participants are recruited, data from each individual are analysed as a separate case.

The present study represents an extension of IPA methodology into analysis of transcripts of therapy conversation. Analysis of case data was carried out in a series of steps.

First, preliminary themes reflecting the meaning of therapy for both client and therapist were identified on the basis of analysis of post-therapy interviews and session reports. In accordance with IPA protocols (Smith, Flowers, \& Larkin, 2009) MSH, KB and HH read this material initially from an open reflective attitude, then re-reading and noting phenomena of interest, then identifying recurring themes.

On the basis of these preliminary themes, members of the research team selected 25 sessions to be transcribed verbatim. Sessions at the start and finish of therapy were transcribed, along with sessions that represented key themes (i.e., session 1-11, 26, 29, 43, 69, 76, 77, 86, 107, 108, 111, 114, 115, 120 and 121). 
Session transcripts were analyzed to identify interaction sequences that exemplified preliminary themes, using sensitizing questions such as: How is the relation between the participants expressed in the dialogue (implicitly and explicitly)? How do they talk about suicidality? How do they talk about trauma related topics? This step also led to the emergence of further themes.

Finally, all themes were reviewed to enable them to be organized into a structure of superordinate and subordinate themes.

Informed by recommendations given by Hill, Knox, Thompson, Williams, Hess and Ladany (2005) we used an independent auditor (JM) to review our understanding of the material and to minimize potential groupthink. The research group met on a regular basis to share their interpretations of specific aspects of the case, to explore the possibility of arriving at a consensus reading, and to agree on further topics for analysis in the next cycle of the inquiry process. These conversations also took account of the reflexive meaning of the case for each member of the research group. The client provided feedback on a draft version of the findings of the study.

\section{RESULTS OF ANALYSIS OF THE THERAPY PROCESS}

The results are presented in five sections, each of which presents a distinctive aspect of the experience of therapy. These aspects that are highlighted did not necessarily occur in chronological order. The first section describes how the client and therapist worked together to accomplish an interactional fit, and establish a recurring pattern of rhythm within dialogue from the first sessions and throughout the therapy. Both client and therapist used the term persistence to characterize their efforts in this domain. The second section outlines therapist and client actions in respect of courage. The third section offers an account of actions that represented the symbolic confirmation of trust, and achievement of an enduring relationship, through metaphor, ritual and use of material objects. Fourth, we present the client's subjective experience of change. (See Table 1 for superordinate and subordinate themes). Finally, an analysis of quantitative contextual data is presented.

Alongside the list of themes summarized above, perhaps the best way to gain a sense of what was helpful in this therapy, is through the words of the client, who read a Norwegian draft of the paper, and she told us that:

It was emotionally strong to read. I cried a lot. You see the point. ... I would like to say something more about what the therapist meant to me, besides being kindly and firm: He dared to be close, allowed himself to be moved, and did not have ready-made solutions. He engaged me in exploring alternatives. He was uncompromising in his own point of view, at the same time being flexible. He validated and respected my destructive survival mechanisms, while simultaneously saying what he meant about them, without giving me more guilt. He took responsibility when I could not. He believed in change. He used humor, did always find something to laugh about. ... What was most important for me was that the bond could be tightened and loosened as required. Being flexible - that was most important. 


\section{Superordinate Theme 1. Persistence}

Both client and therapist talked about how it had been necessary for them to persist with their efforts, through periods of time when little progress appeared to be achieved.

\subsection{Persistence is Built Around Achieving a Good Fit and Creating a Unique Rhythm of Interaction.}

From the start of the therapy there appeared to be a good fit between the two participants, both in personality, expectations and preferences. The client described the interpersonal style of the therapist as "endurable, stable, warm, and empathic, with a good sense of humor". Further, we would describe his relational skills as being direct in his way of talking, steady in his way of being, capable of holding on to his project despite the client's fluctuations, and willing to express uncertainty.

The therapist described the client as "an interesting lady, intellectual, and sharp as a razor. She is rewarding, delivering the goods, no easy way around. She was emotionally present, wise and interesting. She engaged me, she did". As researchers, our observation of the client was that she was a woman with a high level of reflecting function when she was not emotionally activated or dysregulated. She had a very good ability to symbolize her emotions by using metaphors. She gave the therapist sufficient challenge and positive feedback to make him do his best. When listening to the way they talked, our observation of their non-verbal communication was that his voice was deep, embracing, and steady, with authority, often with humor in the tone. By contrast, her voice was soft and hesitant, but well-modulated.

An excerpt from Session 2 illustrates the way they related to each other and initiated their work together.

Client: Where should we begin today?

Therapist: Yes, do you have any reactions after the last session?

C: It was very difficult, lot of difficult thoughts and feelings.

T: Very difficult, yes

C: Got vulnerable. Feel that I talk easily, as if it does not concern me in a way. And when I am alone with my thoughts it becomes very difficult.

(She then tells him about chaos, self-harm, self-hate and suicidal thoughts).

$\mathrm{T}:$... and when you have told me too much.... How much do you think I think that you have told too much?

C: Well to answer that I think I know you too little. But a thought of comfort then is that you are the grown up father, the man. You have talked to many people. I am not that special, that thought gives me comfort. ... But I am also very alert, in case you should get shocked. Did you notice that?

T: No not that clearly. You wonder what I think about you, and then you shovel it away?

C: M-m 
T: And it is all about you in a way? You have been to your first session, and supposedly very skeptical and on the other hand you probably do have a small hope that it will work. And this is sort of a life and death investment for you. And at the same time-the self-loathing.

C: It is about accepting that other people can endure me. A struggle to convince other people that I am not acceptable.

T: Yes, this matches what I am sensing. You are cautious.

C: Ugh, it sounds as disappointment and disappointment, because I imagine that I protect myself, to be prepared.

T: That is just it. So maybe the self-loathing becomes a way to cope against something that is even more frightening: the thought of being condemned by others.

C: How do I deal with that, then?

T: You may be aware of us going too far in the session. If you can tell me, as you do now, I can side with the protecting mechanisms that you need.

This excerpt demonstrates the way in which the therapist acknowledged the extreme difficulty experienced by the client in allowing herself to be known to the therapist, and to trust him. It also exemplifies the use of here-and-now immediacy as a means of anchoring the conversation in the reality of what is happening within the relationship. Further, in the closing interchange in this piece of dialogue, the therapist positions himself as someone who is able to protect the client.

\subsection{The Therapist`s Persistent Presence and Repetitive Reformulations} Contribute to Building Trust and Emotional Safety.

The structure of this therapy comprised regular weekly sessions over many months, combined with flexibility in the form of extra sessions and inpatient care when needed. Together with this regularity we found elements of the therapist's style that we understood as representing a strategy of repetitive and ongoing reformulations. There was a rhythmic interaction pattern that took the form of the client in a sense repetitively singing the same kind of verse throughout the whole therapy - a narrative of shame, self-hate, lack of courage, the fear of losing her love for mother as she has to explore hate and anger towards her. The therapist responded through his chorus: a repetitive song of reformulation about seeing the child's need for love and protection, asking her to look for survival and dignity, offering de-shaming statements. This pattern of interaction occurred throughout the whole therapy, and appeared to represent an underlying precondition for the growth of safety and trust. A part of a transcript demonstrates this duet appearing already in Session 4:

C: The self-loathing just takes over, no job, no social life, why do I not just grasp the opportunity you give me. ... I have these bits of stubbornness she could not take away from me

T: The stubbornness your mother could not quite discipline. So it is not difficult to understand why it is hard to leave your whole defense system in order to feel a bit of the vulnerability that you managed to protect in your childhood 
C: $\mathrm{Mmm}$

T: (insisting) It's no wonder. I do think of the child on the staircase and I wonder what she had to do to endure it all?

C: (sighs) I think (laughs)...That is like, just one episode, I think. I do not know why I select some stories. I do think it is important to offer something in this relation to you, and that it might be a way to make progress and understand something. I do not know how this will develop, but I experienced that in the last session I did some giant steps, and I thought this is too quick, now I got too much for .... I rather pull back all I have told you that feels like my need now. I thought of not coming, and at the same time I get such a huge feeling of cowardice

T: So all that self-blame, about being a coward, is central

$\mathrm{C}$ : That is the strongest concept about me, the suicidal attempts is about being a coward not being able to think all these difficult thoughts to the end- and so it seems I cannot do it alone.

T: But you see-I am very skeptical about calling it cowardice. For me that concept of cowardice is something you use as a part of the self-loathing. And I do notice that you evaluate yourself from the outside, in self-blaming ways instead of from within. So I am looking for if you have a way of challenging your emotional life from within.

C: But that is what I call cowardice. And I have at least two very forbidden feelings - the worst is being egoistic and the next is self-pity.

This pattern of therapist ongoing repetitive steadiness toward the client's struggle with suicidality and self-hurt was a conscious strategy on his part. When interviewed at the end of therapy he stated that:

... she has the idea that she deserves contempt, but when I tell her the opposite repeatedly I do believe it will have the effect of potential repair. Just do as before, be the same person, be the therapist. I do believe in not letting myself be confused by the ups and downs, but to keep on steady with my concept and not become directive.

His persistent reformulation of shame and self-loathing as survival strategies that the client had developed as a little child seemed to have the effect of building trust and making it possible for the client to begin move forward in her life.

\section{Superordinate Theme 2. Courage}

Maybe it is a relationship that is characterized by honesty and courage. That is the right way to say it, I think (Therapist, post-therapy interview).

Both the client and the therapist used the word courageous to describe their own and the other's actions and attitude, and when referring to important steps or movements in the therapy. There were frequent references to courage in session evaluations and post-therapy interviews. In these sequences they described acts of bravery, and then how the process of acting courageously gradually widened and deepened their relationship, making new courageous steps possible. In our analyses we explored both how the participants did courage, as well as what characterized 
the therapeutic process that promoted courageous behavior, both in the client and the therapist. This theme involves both implicit and explicit subjective markers of courageous behavior (both as an experience and as behavior), as well as the potential relational dynamics leading to such behavior. The theme is divided into three sub- categories: involvement, steps of courage undertaken by the client, and steps of courage undertaken by the therapist.

\subsection{The Courage to Involve Oneself}

Already in the reference letter from the general practitioner the notion of courage was introduced. In the post-therapy interview the therapist recounted that:

She (i.e., the client) had an order for treatment that made people turn pale: 'It should be an experienced therapist who also was courageous'. Her general practitioner also wrote that she wanted a therapist who 'gave time, who was patient, secure and trustworthy, but also courageous and who was resistant to manipulation'. That is a tough one, huh!?

The relationship was marked by the courage to endure uncertainty and accept that dangerous issues could be at stake. Both the client and the therapist talked about the risk of involving themselves in the therapeutic relationship, and daring to expose themselves to something new and potentially unpleasant. The therapist dared to involve himself in a therapeutic collaboration with a highly suicidal client and to commit himself for a longer period of time than usual. He reflected that:

I had to say yes to treat a suicidal lady that continued to be suicidal in every session. And I had the feeling that she could kill herself in the middle of the therapy, and I just had to take that risk. So I have never encountered such a tough case as this” (post-therapy interview).

Gradually, the client took the risk of trusting the therapist. She experienced this involvement as potentially dangerous, but also carrying an element of hope. She reported that:

"Well, the first year was dominated by that I did not dare to trust him, in relation to... (hesitates) that he should get tired of me, thinking that it was too demanding, too little progress, a couple of such... But he is absolutely incredible, I have to say”. And she continued: "There have been so many times that I just had to trust (laughs) that he knew what he was doing, and that he has done this for so many years that he knows more than I do. I had to trust him” (post-therapy interview).

\subsection{The Client's Steps of Courage}

The client's courageous behavior appeared early in treatment and evolved throughout the process. She had the courage to share her trauma history, to challenge the shame and feelings of cowardice, gradually daring to acknowledge and tolerate painful emotions, and finally taking the risk of daring to step out into the world and relate to other people.

Daring to transgress shame and share an undisclosed story of immense abuse. Cora started treatment by being "clever". She gave a lot of information about herself, and told about dreadful episodes from her childhood. In the early sessions, she spoke without much affect, but with tremendous delayed impacts and increased self-destructiveness in-between the sessions. 
This pattern of sharing her history, being overwhelmed by emotions afterwards, bringing it back the next session, and using the session to regulate and understand, dominated the initial phase of therapy.

Early, the therapist showed how he understood the client and conveyed his impression of what she was trying to achieve. They negotiated around how to collaborate when difficult topics emerged. After Session 6,

The client wrote: "Approached a very difficult topic for me. Did not reach it all the way through, but maybe later."

The therapist wrote: “Sexually abused as a child. Her mother’s participation. It is difficult for her to talk about it. She knows that it has happened, and that several men were involved, several times. Talked about her anger against her mother and that she was abandoned as a child”.

The therapist did not want to expose her for too much suffering. In the sessions, he articulated that he wanted to maintain her defense system, and showed how he appreciated that this defense was necessary. Simultaneously, he underscored the importance of challenging oneself to promote change. In a caring manner, the therapist helped the client to both get control over overwhelming affects, and to expand her limits of tolerance for painful affects. Gradually, she became able to open up her story.

Somewhat later in treatment she wrote: "Finally talked in detail about sexual abuse! The therapist was listening and caring - no condemnation!” (Session 42). Now Cora could talk about her history without getting overwhelmed by emotion, and they continued to nuance and broaden her understanding and affect tolerance.

When reflecting upon her progress, in the post-therapy interview, the client described this meticulous process, and how she realized, but also dared, to disclose the most shameful and vulnerable topics:

"Yes (pause)...I realize that I have to open those rooms, and to clear up in there. Yes, that has been very hard. It goes so slowly. And then earlier this spring I decided that now...I have to dare... to do the dishes" (Client post-therapy interview).

Exploring and (gradually) tolerating complex emotional states. After approximately six months in therapy, the client consistently demonstrated courage in beginning to explore the possibility of tolerating and owning her own affects.

Recognizing and sharing affects towards the therapist. Following session 26, a session Cora defined as "the best session so far," the client could (through the medium of the session evaluation form) acknowledge the importance of the therapist and the therapy:

It felt as I could come closer to the therapist—and I believe it is because of his ability to make me reflect and see things in connection.

In this session she also shared a fear that he will reject her, and says: "I shared the fear 
without going to pieces. It was a VERY important experience that I endured it and that the therapist did too." She had let the therapist in, explicitly recognized his significance, and put prohibited feelings of fear and dependency into words. Shortly after, there was a period with intensive flashbacks and self-harm, followed by a growing anger towards the therapist, which she dared to express and also to endure. She wrote:

Talked about the feelings that last session put in action, among others I feel anger toward the therapist because of the topic that is excruciating” (Session 31).

After the same session, the therapist wrote:

She cancelled a session, she is angry at me. Backlash with suicidality, eating disturbances, and other self-destructiveness. About owning oneself. I think she is back on the field in her own process.

[This continued into the next session:] Talked about anger and suicidality. Too difficult feelings (Session 32).

[And the therapist wrote:] The last session wasn't as good for her as I thought and hoped. She is signalizing considerable suicidality. Talks about her anger, and that she is afraid it will destroy her if she lets it out. (...) The most important in this session was her suicidality. And for my part it was the feeling of falling short.

They were struggling, and there seemed to be a strain in their relationship. These topics seem to be consolidated in Session 46. The client reported: "Talked about the anger I feel towards the therapist.” The therapist wrote:

She is angry at me because I am "responsible" for these topics coming up. (...) The most important thing that happened was that she feels anger towards me and that she dared to tell me.

During this phase of therapy, Cora took the risk of sharing her feelings about the therapist, and he validated and embraced her expressions. There was a mutual honesty in their relationship. Cora seemed to gain a sense that she was not alone anymore, that she had needs, and that it was possible to express these needs without being condemned. Partly parallel with and partly following this phase, there seemed to be a growing integration of the client's experiences.

Daring to be the one your feelings tell you that you are. At the next phase of therapy, Cora gradually seemed to become aware of a sense of self and personal agency. After session 40 she wrote:

Talked about the connection between three emotions I have felt recently-happiness (to be seen), acceptance, and sadness. I evaluate if I can accept that other people the therapist - may approve my emotions even though I do not do it in the same way".

[Later she continued:] "Courage, emotions. Daring to be the one that your feelings tell you that you are” (Session 66). 
In Session 76 she cried for the first time in treatment, an important moment for her. She wrote: "We talked about emotions. They are not dangerous. And that crying doesn't last endlessly. I cried for the first time!” The therapist wrote: “To make connections between affects and what has happened previously in her life. There are good reasons for feeling anger, anxiety and sorrow. She showed a growing understanding of her own affective reactions.”

In session 77 she recorded that she for the first time had shared an emotion without feeling shame. Subsequent sessions were marked by increased self-compassion and appreciation of her feelings and needs.

Daring to defy prohibited thoughts and feelings towards her mother. Along with a growing ownership of herself, Cora slowly approached conflicting and difficult feelings towards her mother. Her mother was both attachment figure and abuser, and the client struggled with conflicting feelings of love and hate. After session 57 she wrote:

About "prohibited" thoughts and strategies to keep some kind of control over them. There are no safe rooms! Moreover quite OK to say aloud some of those thoughts and feelings that were, and are, present around my mother's death. OK to get the therapist's reaction on that. However - intimidating to talk about.

They worked with memories and the client's feelings towards her mother. Is she permitted not to feel love? Is it possible to hate? She wrote:

The most important that happened today was among others: About not feeling love for my mother, but more like nothing? (Session 86).

[And two sessions later:] About taking the ownership of oneself. Discussed the question about why mother did what she did. A fundamental hate? (Session 88).

Daring to challenge the anxiety and step out into the world. In the early phase of treatment, Cora reported that she is living in a state of solitude, with a very limited social network. She struggled with feelings of shame and anxiety, and the fear of condemnation, in respect of the possibility of developing everyday life relationships. Throughout the process of therapy, they talked about issues around boundaries and connection, both in treatment and outside.

Gradually she became able to challenge her anxiety and dare to relate to some other people. After Session 71 Cora wrote: "Having had 1.5 good weeks! About taking the control myself, daring to set limits for whether others should get involved in "my stuff.' " She continued: "We talked about daring to step out into the world, but simultaneously protecting oneself. Different ways to do this” (Session 83).

\subsection{The Therapist's Steps of Courage}

The therapist on his side took the risk of involving himself in the therapeutic collaboration and committed himself for a lengthy period of time, despite the client's chronic suicidal urges. He held on to his therapeutic strategy without constantly undertaking suicidal assessments or hospitalizing the client. In many ways, he was willing to step out of the 
traditional therapeutic role, by calling her when he was worried about her, and offering extra sessions when she was vulnerable. He also dared to challenge her, and to tell her when he did not know what to do, other than wanting to be there together with her.

The courage to be authentic. The therapist's attitude may be described as genuine and authentic. He dared to connect to the client despite her strong suicidal urges, and became more personal and self-disclosing as the therapy moved on. In the post-therapy interview, he reflected upon the therapeutic relationship and how it had challenged him:

I have made use of everything I know about being authentically present and trustworthy. To follow up what I say, to mean what I say, dare not to have an answer, dare to give an answer, and dare to challenge her. I have the feeling that I have achieved my very best in most areas I know of."

[And he continued:] "I have the feeling that it has been one hundred sessions of improvisation. (...) This is the possibility of the dialogue and the relation. That is more the heading here, you know. It was to try to open the world of possibilities.”

The courage to challenge. Working with a combination of forthrightness and empathy seemed to be a part of the therapist's therapeutic approach: "I want the combination of empathy and curiosity, and also some frankness. I prefer to work with clients who endure me being a bit direct too. I rather take some chances and repair the damage, than move too gently. I believe that I get some profit of being a bit courageous” (post-therapy interview). In this treatment, he recalled one special incident, which both he and the client described as courageous:

I remember one example, not that late in treatment (i.e., Session 16). In addition to permanent injuries after the suicidal attempt, she is also quite overweight. With a quite destructive eating pattern, eats for comfort...Coke, snacks and things like that. But I confronted her with it: "It looks like you also have a weight problem, should we contact the dietitian?” A lady who tells about the most horrible abuse, and then, yes... I remember that it needed lots of courage to be the one who brought that topic into the session. The lady sat there, and the man here, commenting on her in a way. So I remember I was quite proud of myself daring to do that, and I profited on it, you may say.

[Interviewer: Yes, in what way?]

[Therapist:] Well, first of all she said “you're right”, and that she thought that I was brave who dared to ask about it (post-therapy interview, therapist).

The courage to step outside the traditional therapist role. Throughout the treatment the therapist gradually became more personal. In many ways he stepped out of the expected therapeutic role, for example by giving telephone consultations and extra sessions, and calling a friend of the client when concerned about the client's wellbeing. In the post-therapy interview he stated that:

In periods with increased suicidality I have made myself available. I used my own mobile phone, so she got my phone number, you know. (...) So when there have been threats of stopping, I have worked intensively. To get it back on track (post- therapy interview, therapist). 


\section{Superordinate Theme 3. Symbolic Confirmation}

In the last phase of the therapy three significant events occurred that symbolized and reinforced the formation of an enduring relationship of trust.

\subsection{The Golden Heart}

In Session 111 the client asked the therapist if he would be willing to keep a small box with a picture of her mother and a golden heart, which were "the only thing of value I ever got from her." The therapist asked the client if she had thoughts of dying and was requesting that he took care of the memory of her mother. In the session evaluation he wrote:

I suppose I shall keep the heart from mother, even if I do not understand the meaning of it. Does it mean her love for her mother, her hope of her mother's love?

His uncertainty was also in evidence during the session:

C: This is kind of symbolic for me, because I think that if you just could keep it somewhere then I could think of the box with the heart as a symbol of love and that the love will be there afterwards.

T: Left after what?

C: After saying out loud several things, that I have the courage to feel and acknowledge that they are present.

T: So this does not mean that you are going to kill yourself? C: No, that thought did not cross my mind.

T: I just became a little hesitant to be a place where one leaves things.

C: Oh, yes, no, I thought that somebody could keep the box with the heart so I later could open it and then manage the feelings that appear. I do believe in rituals you know.

This event can be understood as representing the willingness of the client to take the next step in the bond formation, by asking for something from another person (the therapist). The therapist did not immediately appreciate the meaning of the ritual, but he nevertheless agreed to keep the heart.

\subsection{The Letter}

Before Session 115, just before the summer holiday, the client wrote a letter to the therapist, describing a shameful incident from her childhood where she engaged in abusive behavior toward another child. She writes in the session evaluation that this letter was the final test. Will he quit now when he gets to know her absolutely most shameful secret? In the post therapy interview she reflected:

...(exhales, pauses, chuckles a bit) I have all the time insisted on that if he really knew me, he had to reject me. But he maintained that it is not true. I can still be in doubt about that. I trust him, but he is only a human being: it must be limits as to what he can endure (...). I had cancelled the next session. He got worried, I learned afterwards and he had contacted a 
friend of mine. When I decided to come back, he was very good. I felt: "Oh my heart, in a way." It was an exhausting session, but when I was on my way to leave he said "I feel that we have managed to reestablish our relation in this session. ... " And that was exactly what I felt, but did not dare to say. ... I think he was very courageous.

\subsection{The Carabiner}

Towards the end of the therapy the therapist increased his direct feedback to the client. The client talked about a friend telling the client how much the client was appreciated:

T: There is something about you and contact ability. You are capable of having contact.

C: I think you are such a patient character, just as my friend is patient, having endurance with me.

T: Yes precisely, and by saying that you do not take it seriously that you are a part of the relation too. You attribute everything to the other person. But this ability to make contact really does play a part here in this room as well, to our relationship. You own a bit of the strength of our relationship as well.

C: (Quiet)

$\mathrm{T}$ : You may speculate on that before our next session.

We get the impression here of a good father who, with authority and love, validates his daughter and gives her wise advice on her way through life.

In Session 120 the client introduces a carabiner (a secure link between two mountaineers joined together by rope) as a symbol of trust, as she looks forward to connecting more openly to family members and a friend. In the last session she gives an actual carabiner to the therapist, as a parting gift.

\section{Superordinate Theme 4. Subjective Experiences of Change}

During the post-therapy interview, Cora was asked about how she experienced the treatment process and what she felt was helpful or hindering. When asked about what came to her mind when thinking about the therapy, she spontaneously said: "He saved my life."

The therapist on his side, when asked about what he thought the client would say about the treatment, he answered: "I guess she would say that the therapy saved her life." The fact that the client is still alive, and that she subjectively reports substantially fewer suicidal thoughts and self-harm, is a kind of basic evidence for her subjective experience of change.

Related to the problems she expressed at the outset of therapy, apart from remaining alive, there seem to be at least three other areas that were central to Cora's experience of change: the ability to trust another human being; expanding the ability to relate to other people; and, tolerating affects to a larger extent. These areas are described below.

In her post- therapy interviews, Cora was invited to identify any areas of disappointment with her therapy, or negative impacts. The session transcripts that were available were also 
reviewed for evidence of negative effects. No such negative or ambivalent outcomes could be detected. As a result, it seems reasonable to conclude, on the basis of the views of both therapist and client, that the therapy was successful.

\section{$\underline{4.1 \text { Basic Trust }}$}

Overall, Cora expressed gratitude for the therapist: "I feel that I have been extremely lucky concerning the therapist. He is durable. Stood by me in all the ditches one can encounter, I believe" (Client post-therapy interview), and a key feature seems to be that the therapist respected her right to commit suicide and her self-harming behavior.

For me it was essential that he accepted my ultimatum and my right to kill myself. The same goes for his attitude towards self-harm. He understood my need for hurting myself and he sustained it. All this shame! And when I finally could show it to him, he was not condemning or frightened. This made it possible for me to build trust” (Client post-therapy interview).

She felt that he respected her boundaries, by not trying to convince her or persuade her to let go of it:

That was decisive and significant for me to dare to...yes, to continue the sessions, and that I could dare to believe that I could profit from the therapy (Client, session 121).

Little by little, she was able to trust him and the therapeutic endeavor. This was also symbolized by her, giving him the carabiner in the last session.

\subsection{Expanding Her Sociability}

When entering treatment, Cora described a life in solitude. A theme throughout the therapy process was how to engage in relationships with people around her. In the last session (121) Cora and the therapist talked about how Cora now experienced people around her (friend, sister) more as opportunities for social contact, rather than as threats. Cora said:

Yes, that is true, and that was exactly what I told her (her friend). Because she has reminded me about it several times, that I am not as alone as I believed all the time. I do have someone. ... And especially regarding my sister, you have helped me to realize that she is there. ...

[Also, in the post-therapy interview Cora talks about this expanded sociability:]

I have resumed contact with my sister. ... So bit by bit, we have established a very good contact. And I now realize that I do not need to be alone with it [i.e., the history/traumas] in my head all the time. Even though we have many sad memories, we also have some good ones about her (i.e., their mother) [Client post-therapy interview].

\subsection{Increased Affect Tolerance}

As described under the section of client courage, it gets evident that the client has involved herself in a meticulous process of gradually recognizing and tolerating both positive 
and negative affects. In the post-therapy interview she says:

Well, it is clear that when I look back, I have... achieved some very big changes. I have to say... because I do not dare to say it with total confidence, but more like that I also have the right to... [inhales] rejoice at things... without immediately feeling guilty about it or put it aside. I dare to hold on to that feeling a bit longer now. ...

[She also describes how she, to a larger extent, can tolerate feelings like shame, guilt, and anxiety:] "Even though I...last summer I had my first experience with anxiety, four or five episodes sending me completely down, and I got very exhausted, very negative, and wanted to give up everything. But that is a bit futile in a way. (...) That anxiety was a disappointment. I struggled a great deal with shame and guilt. We spend much time working on that. And now those feelings do not have such a big grip on me anymore.

By the end of therapy, Cora had not yet reached a stable level of affect consciousness, but she was less afraid of her feelings and able to be more in contact with them.

\section{Termination}

As mentioned above in the section on "The Client," after the three-year therapy described in this case study, Cora was still experiencing distress. She had been admitted to a specialized inpatient program for trauma. She expressed concern about the prospect of attending the trauma program, and it seemed important to her to get a confirmation from the therapist that he would be there when she came back. They also made an agreement that Cora could contact him during the inpatient stay if she wanted. As such, her distress was explicitly shared, and the decision about continued treatment seemed to help her to stay constructively engaged in the trauma program. (As also mentioned above, after the three years of individual therapy covered in the present case study, no data were collected about Cora's response to subsequent therapy.)

\section{CONTEXTUALIZING INFORMATION: COMPARATIVE ANALYSIS OF QUANTITATIVE MEASURES OF PROCESS AND OUTCOME}

\section{The Quantitative Results}

An important limitation of idiographic single-case analysis is that it is not possible to determine whether what is being observed is typical of other cases, or unique to the specific case that is being observed. One strategy for addressing this limitation is to make use of standardized measures that allow points of connections and comparison between the focal case, and the wider population of therapy cases. In this section, comparisons are made between process and outcome data from the current case, and local data from the wider study within which this case was embedded. Where relevant, comparison with general findings for the measures that were deployed is also conducted.

We compared the pre- and post-outcome data in this case to the overall sample of clients from which the case was drawn ( $\mathrm{N}=48$; Rønnestad, 2009), by computing the effect size of the difference scores (i.e., the difference between scores of this case and the mean of the total sample 
divided by the standard deviations on the scores of the total sample; $\mathrm{d}>.20$ is small, $>.50$ is medium, and $>.80$ is large). At pre-therapy, compared to the means in the total sample, Cora presented with high scores on both the OQ-45 (99.2, $d=1.07$, cut-off between clinical and nonclinical domain $=63 / 64$ [Lambert et al., 1996]) and the IIP-C $(1.75, d=0.89$, cut-off between clinical and non-clinical domain $=1.37$ [Solbakken \& Abbass, 2015]). These high scores indicate high levels of distress and poor interpersonal functioning. See Table 2 for means and standard deviations. At post-therapy the client scored approximately at the same level as at intake (OQ45; 99.0, $d=1.71$ and IIP-C; $1.70, d=1.28$ ), indicating no change on these two outcome measures during therapy.

The participants rated their working alliance on WAI throughout the therapy process. There was a gradually rising in scores for both client and therapist (see Figure 1). On average, Cora and her therapist rated the alliance lower than the overall sample, with a large (client $d=$ 1.10) and small (therapist $d=0.34$ ) effect size, respectively. Contrary to the overall sample, and what is common in the literature, the therapist rated the working alliance higher across sessions ( $m=4.89)$ than Cora $(m=4.35)$. In the final session the client rated the alliance 4.83, which is more than one standard deviation below what is reported to be a general level in out-patient samples (final session WAI-S: $5.96, s d=.80$ ), while the therapist's rating (5.58) was in line with general findings (5.50, sd = .88; Busseri \& Tyler, 2003).

\section{Discrepancy with the Qualitative Results}

These results may seem at odds with the qualitative findings previously presented. Taking the quantitative measures at face value would indicate that this is a no-change case, with a relatively poor client-rated alliance. This would be a too simple conclusion. The qualitative data indicate that the client experienced fundamental changes during the therapeutic process, and that the relation to the therapist had been essential in this respect.

Different interpretations of this discrepancy in the qualitative and quantitative data can be offered. It is possible that, in their post-therapy interviews, both therapist and client were seeking to rationalize their enormous investment of time in the case, by highlighting areas of success and minimizing areas of limited progress or disappointment. This is not an interpretation that we favor, on account of the substantial number of positive evaluations of therapy outcome made by both client and therapist in their in-session transcripts and in their Helpful Aspects of Therapy (HAT) forms completed after each session, as well as in their post-therapy interviews.

An alternative interpretation of the no-change scores on the quantitative measures could be that these measures do not capture relevant areas of change for this client. Neither the OQ-45 nor the IIP measure self-harm (note that Cora kept the option of suicide open during the treatment), actual social activity, or conscious awareness of affect-all important behavior indicators of Cora's improvement. Another indicator of Cora's qualitative improvement was her willingness, at the end of the three years, to continue individual therapy and to enter and complete the special, 12-week inpatient trauma program. In line with this, one may understand the three-year episode of therapy described here as a first phase of trauma treatment, helping Cora to stabilize and prepare for more focused trauma work in a second phase. As such, it is not surprising that there were not major changes on the OQ-45 and IIP standardized outcome 
measures.

Specifically, while Cora and her therapist did not explicitly negotiate the goals in the early sessions, they talked about the importance of getting in touch with Cora's feelings, looking at her defenses as survival strategies, increasing her self-compassion, and establishing points of connection to people around her. Looked at from this perspective, the goal was not primarily about reducing Cora's distress but rather about increased awareness of it, leading eventuallyafter the three years, e.g., in the inpatient trauma program and in subsequent individual therapyto a working through of her distressing feelings.

The scores on the working alliance inventory are also interesting in this regard. First, relatively speaking, the client and therapist scores are opposite compared to the overall sample and research in general. Usually, clients tend to rate the alliance higher than their therapists. Second, the client rates the alliance lower than the overall client sample. When investigating her sub-scale scores, she has especially low scores on items loading on the emotional bond component of WAI, e.g., "I believe the therapist likes me." A clinical interpretation of these low scores would be that these questions on WAI touches upon some of her key psychological themes-i.e., trusting other people and believing that she is a loveable person. In the posttreatment interviews she reflected on these topics, and reported that it had not been possible for her to state in a questionnaire that she believed that the therapist liked her (because no one could like her).

We find the discrepancy between qualitative and quantitative data interesting in itself. It touches upon a larger question of what kind of answers we get when triangulating different methods and perspectives. Further elaboration on these questions is offered in the discussion section below.

\section{DISCUSSION}

The findings of this study suggest that, in a case in which a client presented with substantial difficulties around trust and relating to others, the therapist and client were able to make meaningful progress through their mutual investment in a process characterized by persistence and courage, and the collaborative use of symbolic confirmation of their accomplishments. There seemed to be a running interactional dynamic where their persistence could open up for steps of courage, and their steps of courage would provide them with evidence that persistence had made it possible to transcend mere repetition. We learned how they - the client in particular - used the handing over of objects loaded with metaphorical meanings to define a designated moment for their shared confirmation of progress. Based on these findings we will suggest a tripartite model for alliance work in difficult cases, consisting of balancing persistence and courage throughout their running exchanges, as well as turning to symbolic representations of moments of confirmation.

In a theory-building case study, it is not possible to discuss the outcomes of a study in relation to all of the theoretical and empirical sources that could be potentially relevant. In the following sections, the aim of our discussion is to offer some perspectives that invite the reader to consider the meaning and implications of the key themes that emerged from our analysis: 
persistence, courage, and symbolic confirmation.

\section{Persistence}

The first theme of persistence, along with a consistent, recurrent pattern of interaction would appear to confirm the findings arising from other case study analyses of psychotherapy with clients who exhibit a fragile capacity for interpersonal connection, for example, Atwood (2012), Karon (2008) and Terry (2003, 2004, 2005, 2010). Related to this, a study by Imel and colleagues (2014) indicates that vocal synchrony in clinical dyads is related to process and outcome in psychotherapy. The concept of procedural learning (Grigsby \& Stevens, 2000) — that is, the learning of complex activities by repeating them over and over again until all of the relevant neural systems work together automatically to produce the activity-offers a valuable perspective for making sense of the specific relevance of persistence in therapy with clients for whom close relationships are exceptionally difficult. Within the Circle of Security model, Cooper, Hoffmann, Powell and Marvin, (2005) describe the ongoing and repetitive nature of the process of emotional and social development. They suggest that, for a child, their parent represents the safe base and safe haven to which the child may return when in need of comfort and confirmation. When the child has fulfilled his or her need for contact and care, they may resume their exploration of the external world. The parallel to the psychotherapy process, particularly in complicated cases, may be that the therapist repeatedly offers ways to regulate emotion, by communicating his/her caring presence through action and tone of voice, gaze and initiative (Shore, 2003; Stern, 2004). In this way, the therapeutic bonding process in itself may be seen as procedural learning. Thus the client may step-by-step become more able to investigate his or her self and activate their social engagement system (Liotti, 2011; Ogden, Minton, \& Pain, 2006). We believe that this kind of process occurred in the case reported in the present paper. It is also significant that there was a rhythmic quality to the pattern of client-therapist interaction, similar to the "musical" synchrony observed by Trevarthen (1979) in studies of mother-infant play. A similar pattern of "implicit relational knowing" was described as a central aspect by Schechter, Goldblatt, and Maltsberger (2013), in their analysis of a difficult process of bond formation with a suicidal client receiving psychoanalytic psychotherapy.

The relevance of these perspectives is supported by the observation, within the present study, that, for this client, the struggle to establish a relationship of trust encompassed both the rational, grown up part of her, and also the child within. This process may be described as a triangle between the client (and her history), her mother and the therapist. There was repeated cycling back and forth across what was happening between the client and the therapist, and the expression of emotions rooted in abusive childhood experiences. As this cycle proceeded, the client became more able to accept her hatred and anger towards her mother, and at the same time grieve the loss of acceptance and love. And the more she was able to integrate the acceptance from the therapist the more she was able to have empathy with a neglected and abandoned child.

In our efforts to make sense of the specific therapist competencies and actions that, on a repetitive basis, appeared to make a difference to the client, we found it valuable to make connections between the present study, the studies of transference interpretation carried out by Hoglend et al. (2011), and a recent series of theory-building case studies around the concept of therapeutic "immediacy," defined as "disclosures within therapy sessions of how the therapist is 
feeling about the client, about him/herself in relation to the client, or about the therapeutic relationship" (Hill, Sim, Spangler, Stahl, Sullivan, \& Teyber, 2008, p. 298).

Research carried out by Høglend et al. (2011) and Ulberg, Marble, and Høglend (2009) has established that consistent and repeated therapist use of transference interpretations leads to better outcomes in clients with similar profiles to that of Cora. In the present case, however, the therapist made use of responses that went beyond the type of transference interpretation described by that research group (Ulberg, Amlo, \& Høglend, 2014; Ulberg et al., 2014), to encompass self-referential content in which the therapist disclosed aspects of his own thoughts and emotions in relation to therapist-client interactions that had occurred (Veach, 2011).

'Many of the interventions used by the therapist could be understood as a combination of transference interpretation and therapeutic immediacy, as defined above . Case analyses by Hill et al. (2008); Kasper, Hill, \& Kivlighan (2008), and Mayotte-Blum et al. (2012) have showed that skilful use of immediacy on the part of the therapist was perceived by clients as showing caring and helpfulness, tended to facilitate expression of painful emotional material, and contributed to the client being able to develop closeness with other people in their life.

Why might it have been helpful for Cora to have been exposed to such interventions? One way of making sense of this would be to speculate, that, in the context of early relational trauma, (a) repeated invitations to pay attention to what was happening within the present relationship (i.e., preliminary transference interpretation), accompanied by (b) authentic expression of the internal state of the therapist (immediacy) along with occasional reminders that the present relationship fundamentally differed from previous abusive relationship (i.e., advanced transference interpretation), could be a good way to learn how to trust another human being. It seems possible that either transference interpretations alone, or immediacy responses alone, might not have achieved such an outcome.

\section{Courage}

The second theme of courage emerged as a key factor in the success of therapy in this case. The topic of courage has received relatively little attention in the psychotherapy research and clinical literature. It is possible to identify different types of courage, or at least different types of situations that call for courage.

Pury, Kowalski, and Spearman (2007) distinguish between general courage, where the person acts courageously compared to how people in general would be expected to act in that situation; i.e., the risk involved would be present for everyone, and personal courage, defined as actions which are only courageous given the context of the actor's personal limitations (p. 101).

In the context of psychotherapy, we probably mostly operate in the domain of personal courage, where there are internal obstacles and struggles that are to be overcome. Different authors have tried to describe and disentangle what personal courage might be. The existentialist writer Rollo May (1984) distinguishes between different forms of courage. Social courage, he says, is needed for relating to other human beings, and for the ability to risk your own sense of self or "who I am" in hopes of achieving a significant and personal relationship. This form of 
courage was apparent in the bond formation process described in this case, for example, the client's ability to transgress her fear of closeness and dependency and finally being capable of trusting and relating to the therapist.

The philosopher Daniel Putman (2010) has suggested that the courage to confront and work through psychological problems involves facing our deep-seated fear of psychological instability, or what Goodwin (1986, in Putman, 2010) describes as "fear of a kind of psychic death". The different steps of courage we describe in this case would appear to be consistent with these ideas.

Further, according to Shelp (1984), courage is a prerequisite not only for clients, but also for health professionals. In his view, courage is an essential virtue that physicians must have in order to effectively treat patients. Moreover, instilling courage through "encouragement" is required in any profession that embodies care and concern (p. 358). According to Shelp (1984), there are some necessary components of courage, such as freedom of choice, fear of a situation, and the willingness to take risks in a situation with an uncertain, but morally worthy end. In the present case, we found that both participants may be described as courageous in this sense. The client struggled against her own internal demons, fluctuating between her longings and fears for trust and belonging, while the therapist dares to accept the client's persistent suicidal wish and stays authentically present in the relationship despite uncertainty.

In relation to the theme of therapist courage, it can be noted that working with suicidal clients is generally considered by therapists to be highly demanding and stressful (Hendin, Haas, Maltsberger, Szanto, \& Rabinowicz, 2004). It is possible, therefore, that the salience of therapist courage in the analysis of the present case may have been heightened in this particular case, and that therapeutic work with other clients who have extreme difficulty in forming emotional bonds, but are not suicidal, may follow a different trajectory.

\section{Symbolic Markers}

An unusual and striking aspect of the present case was the significance, toward the end of therapy, of client-initiated symbolic markers of the accomplishment of trust and emotional connection. This represents the third theme. Several studies have examined the experience of client gift-giving, in terms of client gratitude and possible boundary violation (Knox, 2008; Knox, DuBois, Hess, Smith, \& Hill, 2009; Knox, Hess, Williams, \& Hill, 2003).

In the present case it was clear that the client was not merely offering the therapist a gift, in gratitude for his efforts and kindness. Arthern and Madill (1999) explored the meaning of client use of transitional objects within therapy-mainly objects that the client is given by their therapist, or takes from the therapist's room. These objects were interpreted by Arthern and Madill (1999) as representing the safe space afforded by the therapist and therapy room, and as physical tokens that the client could hold on to, and serve as tangible reminders of that space. In the present case, the symbolic objects offered by the client did not seem to operate in this fashion, because they were not retained by the client. However, both the present study and Arthern and Madill (1999) draw attention to the importance of client agency (these are events that are very much initiated by the client) and the emotional meaning of material objects. In 
many indigenous therapies, and in contemporary arts therapies, the important role of material objects is well established. The findings of the present study suggest that material objects might also have the potential to augment the effectiveness of other therapeutic approaches.

\section{Limitations of The Study}

It is essential to acknowledge the limitations of this study. Most likely, other patterns of constructive therapeutic work with individuals who have survived emotional trauma are possible, and will be identified in further research. Other researchers may have arrived at different conclusions, based on the case material that was available. Nevertheless, the analysis of this case was based on exhaustive and critical interpretation of a rich data set with a particular sensitivity to the extreme relational difficulties in the life of this client and the long time it took for them to reach a point at which the client felt capable of trust. It is to be hoped that, at the least, these findings will provide a basis for further in-depth case-based analysis of what is helpful (and hindering) for clients who present such issues in therapy.

The material on this case comprised almost 500 pages of documentation, and was analyzed by a team of four experienced researchers who met regularly over a four-year period. Aspects of the analysis were presented to a variety of audiences, who introduced valuable further perspectives. Despite the extent of these efforts, it is possible to identify a number of limitations of the study. First, the data may be incomplete. Only 25 (21\%) of therapy sessions were transcribed. It is possible that untranscribed sessions may have included evidence of change processes and events that would have contributed to different conclusions about the case. It was not possible, for health reasons, to obtain the comments of the therapist on the case analysis. Only limited data were available about everyday life event outside of the therapy that may have shaped the healing trajectory of the client. Information was limited to two sources (client and therapist) and did not include perceptions of significant individuals in the life of the client.

Second, there might be limitations of the data analysis strategy. By using the post-therapy interviews as the starting-point for the analysis, it is possible that the members of the research team were over-influenced by the conclusions about the case that the therapist and client were able (or willing) to articulate at these meetings. An analytic strategy that started with the first session and working forward, may have allowed the team to uncover implicit or unconscious aspects in the post-therapy accounts of therapist and client. It may have been valuable to incorporate aspects of the Hermeneutic Single Case Efficacy Design (HSCED; Elliott, 2002) methodology as a more rigorous means of determining the outcome status of the case. It might have been valuable to carry out analysis of therapist response style (e.g., use of immediacy and transference interpretation) using validated rating scales.

Finally, there might be limitations of the data collection strategy. The measures used in the study reflected generic aspects of the process and outcome of therapy. It is possible that measures that were more specifically tailored to the issues presented by this particular client (e.g., trauma, attachment and suicidality) could have provided valuable additional information about change in these domains. Interviews were conducted independently of analysis of other data. If the post- therapy interviews had been informed by prior analysis of process and outcome data, it would have been possible, at the time, to explore the apparent, above-discussed 
discrepancy between qualitative and quantitative estimates of outcome (for more on this discrepancy, see below).

\section{Implications and Concluding Remarks}

\section{Practical Implications for Therapeutic Work with Extremely Distrustful Clients}

We believe that the findings of this case have important practical implications, in relation to therapeutic work with individuals who demonstrate extreme difficult in trusting other people. The findings of the case suggest that it is valuable for therapists working with such clients to be willing to repeat facilitative, affirming messages, and trust-inducing sequences of interaction, often enough for procedural learning to occur. The qualities of persistence in a relationship will open up for steps of courage, steps that might be challenging, but not detrimental to their work. Courageous acts are more one-sided, with the capacity to take the relationship one step further, but also with the danger of making irreversible setbacks. The use of objects to be handed over from the client to the therapist (or similar symbolic acts - see Terry, 2010) both individualize and reify the accomplishment of trust, thus making the outcome more real, and beyond any doubt.

\section{The Discrepancy Between the Qualitative and Quantitative Findings}

We would like to offer some reflections on an important methodological issue that arose in this case, in relation to the discrepancy between the portrayal of outcome derived from qualitative data, and the findings arising from standardized measures. Our experience has been that some audiences for this case study have assumed that our analysis must be mistaken, and that the quantitative data must be correct: in other words, Cora did not benefit from therapy. This issue has the potential to open up major issues around the nature of knowledge, which are beyond the scope of the present paper. It is perhaps sufficient to offer two observations.

First, discrepancies between qualitative and quantitative outcome and process data have been reported in other psychotherapy case studies (see, for example, Elliott et al., 2009). Second, such discrepancies come as no surprise to anyone familiar with research into psychological assessment. In an authoritative review of this area, Meyer, et al. (2001) conclude that distinct assessment methods, each of them valid in their own right, need to be regarded as offering unique sources of information. Any particular assessment method has its own strengths (capacity to detect certain phenomena) and weaknesses. There are good reasons to be appropriately skeptical about information gleaned from any resource-qualitative or quantitative.

An appreciation of method variance leads to an intriguing set of implications for practice. If Cora had been receiving therapy in a situation in which the length of therapy was determined by analysis of scores from weekly outcome measures, as is sometimes done, she would have been fairly readily designated as "not on track," with the possibility of being referred to another service, or required to terminate. Cora's case suggests that when such monitoring leads to finding a case "not on track," it be followed up with a qualitative analysis of the case's status, before terminating the case. 


\section{Therapist Expertise}

Finally, in relation to the investigation of therapist expertise, the findings of this case study suggest that it may be valuable, along with other methodological approaches, to analyze the forms of therapist action that seem to be significant within specific cases. It is possible that the analysis of "difficult" cases represents a domain in which it is relatively more straightforward to identify the types of therapist action that make a difference. For example, it seems unlikely that a case of brief therapy with a well-adjusted client would highlight persistence, courage and use of symbolic resources as salient therapist actions, because these competencies would be less likely to be required in relatively straightforward cases. The findings of this study also open up the possibility that a more holistic approach to understanding the potency of therapist responses in the areas of immediacy and transference interpretation will yield a richly promising direction for research and training around therapist expertise.

\section{REFERENCES}

Alden, L. E., Wiggins, J. S., \& Pincus, A. L. (1990). Construction of circumplex scales for the Inventory of Interpersonal Problems. Journal of Personality Assessment, 55, 521-536. doi:10.1080/00223891.1990.9674088

Anderson, T., Ogles, B.M., Patterson, C.L., Lambert, M.J., \& Vermeersch, D.A. (2009). Therapist effects: Facilitative interpersonal skills as a predictor of therapist success. Journal of Clinical Psychology, 65, 755-768. doi: 10.1002/jclp.20583

Arthern, J., \& Madill, A. (1999). How do transitional objects work?: The therapist's view. British Journal of Medical Psychology, 72 (1), 1-21. doi: 10.1348/000711299159754

Atwood, G.E. (2012). The abyss of madness and human understanding. Pragmatic Case Studies in Psychotherapy, 8(1), Article 4, 49-59. Available: pcsp.libraries.rutgers.edu, doi: http://dx.doi.org/10.14713/pcsp.v8i1.1121

Bramley, N., \& Eatough, V. (2005). The experience of living with Parkinson's disease: An interpretative phenomenological analysis case study. Psychology \& Health, 20, 223- 235. DOI:10.1080/08870440412331296053

Busseri, M. A. \& Tyler, J. D. (2003). Interchangeability of the Working Alliance Inventory and Working Alliance Inventory, Short Form. Psychological Assessment, 15(2), 193- 197. doi: 10.1037/1040-3590.15.2.193

Chow, D.C., Seidel, J.A., Miller, S.D., Kane, R.T., Thornton, J.A., \& Andrews, W.P. (2015). The role of deliberate practice in the development of highly effective psychotherapists. Psychotherapy, 52, 337-345. doi:10.1037/pst0000015

Cooper, G., Hoffman, K., Powell, B., \& Marvin, R. (2005). The Circle of Security Intervention. In L. J. Berlin, Y. Ziv, L. M. Amaya-Jackson, \& M. T. Greenberg (Eds.), Enhancing Early Attachments: Theory, Research, Intervention, and Policy. New York: Guilford Press.

Eatough, V., \& Smith, J.A. (2006a). I feel like a scrambled egg in my head: An idiographic case study of meaning making and anger using interpretative phenomenological analysis. Psychology and Psychotherapy: Theory, Research and Practice, 79, 115-135. DOI: $10.1348 / 147608305 X 41100$

Eatough, V., \& Smith, J.A. (2006b). I was like a wild wild person: Understanding feelings of anger using interpretative phenomenological analysis. British Journal of Psychology, 97, 
483-498. DOI: 10.1348/000712606X97831

Elliott, R. (2002). Hermeneutic single-case efficacy design. Psychotherapy Research, 12 (1), 1 21. doi:10.1080/713869614

Elliott, R., Partyka, R., Wagner, J., Alperin,R., Dobrenski, R., Messer, S.B., Watson, J.C., \& Castonguay, L.G. (2009). An adjudicated Hermeneutic Single Case Efficacy Design study of experiential therapy for panic/phobia. Psychotherapy Research, 19, 543-557.

Ellis, T.E., Allen, J.G., Green, K.L., Jobes, D.A., \& Nadorff, M.R. (2012). Collaborative assessment and management of suicidality in an inpatient setting: results of a pilot study. Psychotherapy, 49, 72-80. DOI: 10.1037/a0026746

Grigsby, J., \& Stevens, D. (2000). Neurodynamics of personality. New York: Guilford Press.

Hatcher, R. L. \& Gillapsy, J. A. (2006). Development and validation of a revised short version of the Working Alliance Inventory. Psychotherapy Research, 16 (1), 12-25. doi:10.1080/10503300500352500

Heinonen, E., Lindfors, O., Härkänen, T., Virtala, E., Jääskeläinen, T, \& Knekt, P. (2014). Therapists' professional and personal characteristics as predictors of working alliance in short-term and long-term psychotherapies. Clinical Psychology \& Psychotherapy, 21, 475-494. doi: 10.1002/cpp.1852

Heinonen, E., Lindfors, O., Laaksonen, M.A., \& Knekt, P. (2012). Therapists' professional and personal characteristics as predictors of outcome in short- and long-term psychotherapy. Journal of Affective Disorders, 138, 301-312. doi:10.1016/j.jad.2012.01.023

Hendin, H., Haas, A., Maltsberger, J., Szanto, K., \& Rabinowicz, H. (2004). Factors contributing to therapist's distress after the suicide of a patient. American Journal of Psychiatry, 161, 1442-1446. doi:10.1176/appi.ajp.161.8.1442

Hill, C. E., Knox, S., Thompson, B. J., Williams, E. N., Hess, S. A., \& Ladany, N. (2005). Consensual qualitative research: An update. Journal of Counseling Psychology, 52(2), 196-205. doi: 10.1037/0022-0167.52.2.196

Hill, C. E., Sim, W., Spangler, P., Stahl, J., Sullivan, C., \& Teyber, E. (2008). Therapist immediacy in brief psychotherapy: Case study II. Psychotherapy, 45 (3), 298-315. doi: 10.1037/a0013306

Høglend, P., Hersoug, A.G., Bøgwald, K.P., Amlo, S., Marble, A., Sørbye, Ø., Røssberg, J.I., Ulberg, R., Gabbard, G.O., \& Crits-Christoph, P. (2011). Effects of transference work in the context of therapeutic alliance and quality of object relations. Journal of Consulting and Clinical Psychology, 79, 697-706. doi:10.1037/a0024863.

Imel, Z. E., Barco, J. S., Brown, H., Baucom, B. R., Baer, J. S., Kircher, J., \& Atkins, D. C. (2014). The association of therapist empathy and synchrony in vocally encoded arousal. Journal of Consulting Psychology, 61 (1), 146-153. doi:10.1037/a0034943

Karon, B.P. (2008). An "incurable" schizophrenic: The case of Mr. X. Pragmatic Case Studies in Psychotherapy, 4(1), Article 1, 1-24. Available: pcsp.libraries.rutgers.edu, doi: http://dx.doi.org/10.14713/pcsp.v4i1.923

Kasper, L. B., Hill, C. E., Kivlighan, D. M. (2008). Therapist immediacy in brief psychotherapy: Case study I. Psychotherapy, 45 (3), 281-97. doi: 10.1037/a0013305.

Killingmo, B. (1989). Conflict and deficit: Implications for technique. International Journal of Psychoanalysis, 70, 65- 79.

Knox, S. (2008). Gifts in psychotherapy: Practice review and recommendations.

Psychotherapy: Theory, Research, Practice, Training, 45, 103-110. doi: 10.1037/ 00333204.45.1.103 
Knox, S., DuBois, R., Hess, S.A., Smith, J., \& Hill, C.E. (2009). Clients’ experiences giving gifts to therapists. Psychotherapy: Theory, Research, Practice, Training, 46, 350-361. doi: 10.1037/a0017001

Knox, S., Hess, S. A., Williams, E. N., \& Hill, C. E. (2003). "Here’s a little something for you”: How therapists respond to client gifts. Journal of Counseling Psychology, 50, 199-210. doi: 10.1037/0022-0167.50.2.199

Lambert, M., J., Burlingame, G. M., Umphress, V., Hansen, N. B., Vermeersch, D. A., Clouse. G. C., \& Yanchar, S. C. (1996). The reliability and validity of the Outcome Questionnaire. Clinical Psychology and Psychotherapy, 3, 249-258. doi: 10.1002/(SICI)1099-0879(199612)

Liotti, G. (2011). Attachment disorganization and the Controlling Strategies: An illustration of the Contribution of Attachment Theory to Developmental Psychopathology and to Psychotherapy Integration. Journal of Psychotherapy Integration, 21 (3), 232-252. doi: 10.1037/a0025422

Llewelyn, S.P., Elliott, R., Shapiro, D.A., Firth, J., \& Hardy, G. (1988). Client perceptions of significant events in prescriptive and exploratory periods of individual therapy. British Journal of Clinical Psychology, 27, 105-114. doi: 10.1111/j.2044-8260.1988.tb00758.x

May, R. (1994). Mot til å skape. Oslo: Aventura. (Original title: The courage to create) Mayotte-Blum, J., Slavin-Mulford, J., Lehmann, M., Pesale, F., Becker-Matero, N., \& Hilsenroth, M. (2012). Therapeutic immediacy across long-term psychodynamic psychotherapy: An evidence-based case study. Journal of Counseling Psychology, 59 (1), 27-40. doi: /10.1037/a0026087

McLeod, J. (2010). Case study research in counselling and psychotherapy. London: Sage. Meyer, G.J., Finn, S.E., Eyde, L.D., Kay, G.G., Moreland, K.L., Dies, R.R., Eisman, E.J., Kubiszyn, T.W., \& Reed, G.M. (2001). Psychological testing and psychological assessment: A review of evidence and issues. American Psychologist, 56, 128-165. http://dx.doi.org/10.1037/0003-066X.56.2.128

Miller, S. D., Hubble, M. A., Chow, D. L., \& Seidel, J. A. (2013). The outcome of psychotherapy: Yesterday, Today, Tomorrow. Psychotherapy, 50, 88 - 97. doi: 10.1037/a0031097

Munich, R.L., \& Allen, J.G. (2003) Psychiatric and sociotherapeutic perspectives on the difficult-to-treat patient. Psychiatry, 66, 346-357. doi:10.1521/psyc.66.4.346.25438

Nissen-Lie, H. A., Monsen, J. T., \& Ronnestad, M. H. (2010). Therapist predictors of early patient-rated working alliance: A multilevel approach. Psychotherapy Research, 20, 627646. doi:10.1080/10503307.2010.497633

Nissen-Lie, H.A., Rønnestad, M.H., Høglend, P.A., Havik, O.E., Solbakken, O.A., Stiles, T.C., \& Monsen, J.T. (2015). Love yourself as a person, doubt yourself as a therapist? Clinical Psychology and Psychotherapy. doi: 10.1002/cpp.1977

Oddli, H. W., Benum, K., Halvorsen, M. S., \& Stänicke, E. (2015, June). Expert therapists as clinicians and research participants. Presentation at the Society for Psychotherapy Research, international conference in Philadelphia, US.

Oestrich, I.H. (1992). A cognitive-behavioral approach to panic disorder in a woman with a history of incest: a case study. Journal of Cognitive Psychotherapy, 6, 125-136.

Ogden, P., Minton, K., \& Pain, C. (2006). Trauma and the body. A sensorimotor approach to psychotherapy. New York, NY: W. W. Norton \& Company. 
Pearlman, L. A., \& Courtois, C. A. (2005). Clinical applications of the Attachment framework: Relational treatment of complex trauma. Journal of Traumatic Stress, 18, 449-460. doi: $10.1002 /$ jts.20052

Pearson, J. L., Cohn, D. A., Cowan, P. A., \& Cowan, C. (1994). Earned- and continuoussecurity in adult attachment: Relation to depressive symptomatology and parenting style. Development and Psychopathology, 6, 359-373. doi:10.1017/S0954579400004636

Pury, C. L. S., Kowalski, R. M., \& Spearman, J. (2007). Distinctions between general and personal courage. The Journal of Positive Psychology, 2 (2), 99 - 114. doi: 10.1080/17439760701237962

Putman, D. (2010). Philosophical Roots of the Concept of Courage. In C. L. Pury, S., J. Lopez, J. Shane (Eds.), The psychology of courage: Modern research on an ancient virtue, pp. 922. Washington, DC, US: American Psychological Association. doi: 10.1037/12168-001

Quinn, M.C., Schofield, M.J., \&Middleton, W. (2012). Successful psychotherapy for psychogenic seizures in men. Psychotherapy Research, 22, 682-698. doi:10.1080/10503307.2012.704085

Rønnestad, M. H. (2009). An intensive process-outcome study of the interpersonal aspects of psychotherapy. Application for the Research Council of Norway, available at: http://www.sv.uio.no/psi/english/people/aca/helgero/process\%20_outcome_study\%5B1\% 5D.pdf

Rønnestad, M. H., Gullestad, S., Halvorsen, M. S., Haavind, H., Lippe, A. L.V., Nissen-Lie, H. A., \& Reichelt, S. (2014, June). The outcomes of therapies conducted by highly experienced therapists. Presentation at the Society for Psychotherapy Research, international conference in Copenhagen, Denmark.

Sandell, R., Blomberg, J., Lazar, A., Carlsson, J., Broberg, J., \& Schubert, J. (2000). Varieties of long-term outcome among patients in psychoanalysis and long-term psychotherapy: a review of findings in the Stockholm Outcome of Psychoanalysis and Psychotherapy Project (STOPP). The International Journal of Psycho-Analysis, 81, 921-942.

Sandell, R., Lazar, A., Grant, J., Carlsson, J., Schubert, J., \& Broberg, J. (2007). Therapist attitudes and patient outcomes: II. Therapist attitudes influence change during treatment. Psychotherapy Research, 17, 196-204. doi:10.1080/10503300600608439

Saunders, R., Jacobvitz, D., Zaccagnino, M., Beverung, L.M., \& Hazen, N. (2011). Pathways to earned-security: The role of alternative support figures. Attachment \& Human Development, 13, 403-420. doi: 10.1080/14616734.2011.584405

Saxon, D., \& Barkham, M. (2012). Patterns of therapist variability: therapist effects and the contribution of patient severity and risk. Journal of Consulting and Clinical Psychology, 80, 535-546. doi: 10.1037/a0028898

Schechter, M., Goldblatt, M., \& Maltsberger, J.T. (2013). The therapeutic alliance and suicide: when words are not enough. British Journal of Psychotherapy, 29, 315-328. doi: 10.1111/bjp.12039

Shelp, E. E. (1984). Courage: a neglected virtue in the patient-physician relationship. Social science and medicine, 18 (4), 351-60.

Shore, A. (2003). Affect regulation and repair of the self. New York: Norton.

Smith, J.A. (2011). Evaluating the contribution of interpretative phenomenological analysis. Health Psychology Review, 5, 9-27. doi: 10.1080/17437199.2010.510659

Smith, J.A., Flowers, P., \& Larkin, M. (2009) Interpretative Phenomenological Analysis: theory, 
method and research. London: Sage.

Solbakken, O. A. \& Abbass, A. (2015). Intensive short-term dynamic residential treatment program for patients with treatment-resistant disorders. Journal of affective disorders, 181, 67-77. DOI: 10.1016/j.jad.2015.04.003

Stein, H., \& Allen, J.G. (2007). Mentalizing as a framework for integrating therapeutic exposure and relationship repair in the treatment of a patient with complex posttraumatic psychopathology. Bulletin of the Menninger Clinic, 71, 273-290. doi: 10.1521/bumc.2007.71.4.273

Stern, D. W. (2004). The present moment in psychotherapy and everyday life. New York: Norton.

Stiles, W. B. (2007). Theory-building case studies of counselling and psychotherapy. Counselling and Psychotherapy Research, 7, 122-127. doi:10.1080/14733140701356742

Terry, P. (2003). Working with psychosis part 1 - grieving the damage of a psychotic illness. Psychodynamic Practice, 9, 123-140. doi:10.1080/1353333031000104802

Terry, P. (2004). Working with psychosis part 2 - encounters with an Omnipotent super-ego. Psychodynamic Practice, 10, 45-59. doi:10.1080/14753630310001656036

Terry, P. (2005). Working with psychosis part 3 - struggling to contain madness - losing and recovering a capacity to think. Psychodynamic Practice, 11, 29-39. doi:10.1080/14753630400030106

Terry, P. (2010). Working with psychosis Part 4: Therapy online - ending by email. Psychodynamic Practice, 16, 151-163. doi:10.1080/14753631003688126

Tracey, T.J.G., Wampold, B.E., Lichtenberg, J.W., \& Goodyear, R.K. (2014). Expertise in psychotherapy: An elusive goal? American Psychologist, 69, 218-229. http://dx.doi.org/10.1037/a0035099

Trevarthen, C. (1979). Communication and cooperation in early infancy: A description of primary intersubjectivity. In M. Bullowa (Ed.) Before speech: The beginning of interpersonal communication. New York: Cambridge University Press.

Ulberg, R., Amlo, S., \& Høglend, P. (2014). Manual for transference work scale; a micro-analytical tool for therapy process analyses. BMC Psychiatry, 14, 291. http://www.biomedcentral.com/1471$244 \mathrm{X} / 14 / 291$

Ulberg, R., Critchfield, K.L., Amlo, S., Marble, A., \& Høglend, P. (2014). Transference interventions and the process between therapist and patient. Psychotherapy, 51, 258-269. doi:10.1037/a0034708

Ulberg, R., Marble, A., \& Høglend P. (2009). Do gender and level of relational functioning influence the long-term treatment response in dynamic psychotherapy? Nordic Journal of Psychiatry, 63, 412-419. doi:10.1080/08039480903009126

Veach, P.M. (2011). Reflections on the meaning of clinician self-reference: are we speaking the same language? Psychotherapy, 48, 349-358. doi: 10.1037/a0025908 
Table 1. Superordinate and subordinate themes

\begin{tabular}{|c|c|}
\hline Superordinate themes & Subordinate themes \\
\hline \multirow[t]{2}{*}{ 1. Persistence } & \\
\hline & $\begin{array}{l}\text { 1.1. Achieving a good fit and creating a unique rhythm } \\
\text { of interaction } \\
\text { 1.2. Therapist persistent presence and repetitive } \\
\text { reformulations }\end{array}$ \\
\hline \multirow[t]{2}{*}{ 2. Courage } & \\
\hline & $\begin{array}{l}\text { 2.1.The courage to involve oneself } \\
\text { 2.2.The client's steps of courage } \\
\text { - Daring to transgress shame and share an } \\
\text { undisclosed story of immense abuse } \\
\text { - Exploring and (gradually) tolerating complex } \\
\text { emotional states } \\
\text { 2.3.The therapist's steps of courage } \\
\text { - The courage to be authentic } \\
\text { - The courage to challenge } \\
\text { - The courage to step outside the traditional } \\
\text { therapist role }\end{array}$ \\
\hline
\end{tabular}

3. Symbolic confirmation

3.1.The golden heart

3.2. The letter

3.3. The carabiner

4. Subjective experiences of change

4.1. Basic trust

4.2. Expanded sociability

4.3 Increased affect tolerance 
Table 2. Scores on process and outcome measures

\begin{tabular}{|c|c|c|c|c|}
\hline & \multicolumn{4}{|c|}{ Average session scores on WAI-SR } \\
\hline & \multicolumn{2}{|l|}{ Case } & \multicolumn{2}{|c|}{ Project sample (SD) $^{\mathrm{a}}$} \\
\hline Client WAI & 4.35 & & $5.33(0.89)$ & \\
\hline \multirow[t]{4}{*}{ Therapist WAI } & 4.89 & & $5.15(0.77)$ & \\
\hline & \multicolumn{4}{|c|}{ Treatment outcome measures } \\
\hline & \multicolumn{2}{|c|}{ Case } & \multicolumn{2}{|c|}{ Mean, project sample (SD) } \\
\hline & Pre & Post & Pre & Post \\
\hline$O Q-45^{c}$ & 99.20 & 99.00 & $75.06(22.54)$ & $55.23(25.56)$ \\
\hline IIP-C ${ }^{d}$ & 1.75 & 1.70 & $1.28(0.53)$ & $1.01(0.54)$ \\
\hline
\end{tabular}

${ }^{a}$ Oddli, Benum, Halvorsen, \& Stänicke (2015, June).

b Rønnestad, Gullestad, Halvorsen, Haavind, Lippe, Nissen-Lie, \& Reichelt (2014, June).

${ }^{\text {C }}$ Clinical cut-off $=63 / 64$ (Lambert, et al., 1996).

$\mathrm{d}$ Clinical cut-off $=1.37$. Note that this value is calculated in a sample of patients who had repeated prior treatment failure for current mental disorder and sufficient dysfunction to warrant hospitalization (Solbakken \& Abbass, 2015), and is probably higher than in general outpatient samples.

Note. WAI-SR = Working Alliance Inventory—Short Form

OQ-45 = Outcome Questionnaire

IIP-C = Inventory of Interpersonal Problems 
A Life-Saving Therapy: The Theory-Building Case of "Cora"

M. S. Halvorsen, K. Benum, H. Haavind, \& J. McLeod

Pragmatic Case Studies in Psychotherapy, http://pcsp.libraries.rutgers.edu

Volume 12, Module 3, Article 1, pp. 158-193, 10-16-16 [copyright by authors]

Figure 1. Client and therapist overall WAI scores

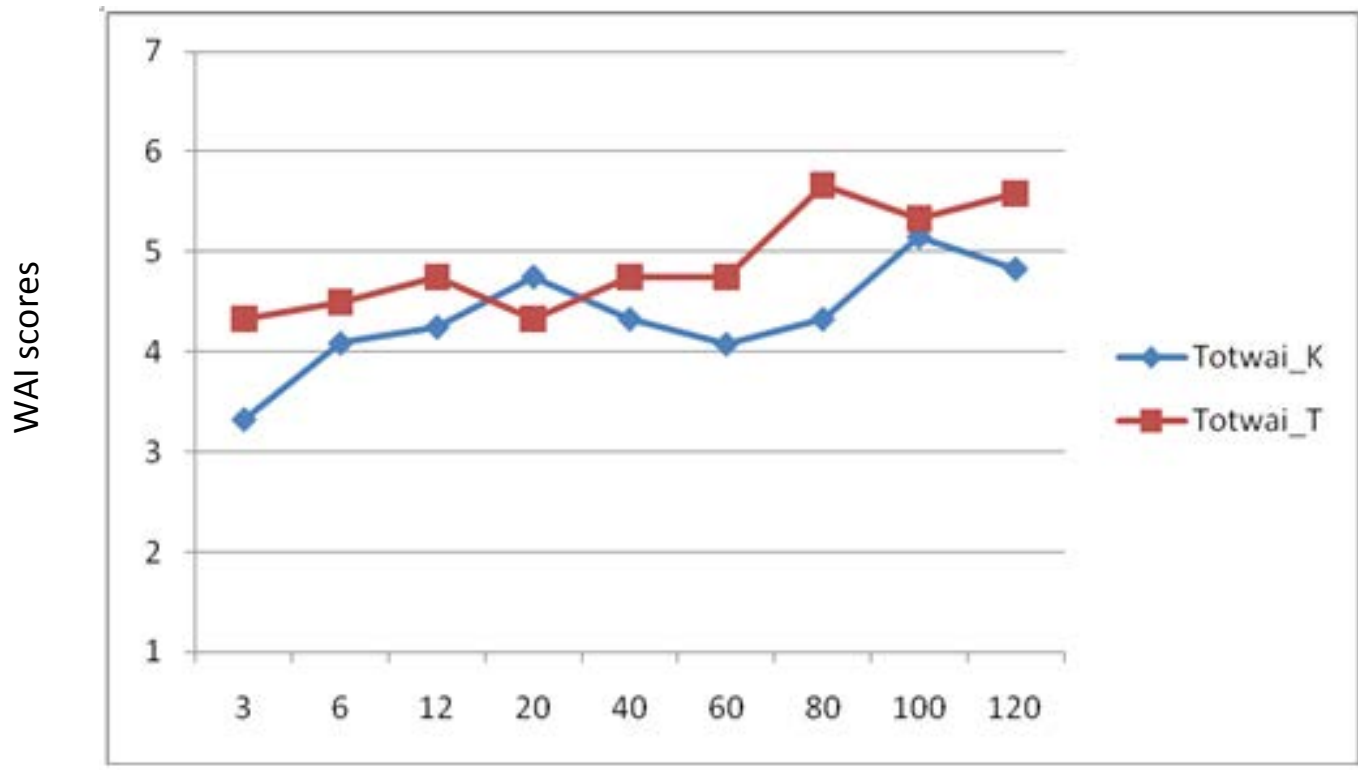

Sessions 